\title{
Macrocephaly-short stature-paraplegia syndrome
}

INSERM

\section{Source}

INSERM. (1999). Orphanet: an online rare disease and orphan drug data base.

Macrocephaly-short stature-paraplegia syndrome. ORPHA:2427

Macrocephaly-short stature-paraplegia syndrome is characterized by macrocephaly and midface hypoplasia, intellectual deficit, short stature, spastic paraplegia and severe central nervous system anomalies (hydrocephalus and Dandy-Walker malformation). It has been described in two unrelated adults. 